\title{
G scmem \\ Facial Phenotype Changes and Its Impact in Quality of Life of Acromegaly Patients
}

\section{Maria-Antonia Martínez-Momblan}

Escuela de Enfermería de la Facultad de Medicina y Ciencias de la Salud https://orcid.org/0000-00025364-5270

\section{Sergio Alonso}

Escuela de Enfermeria de la Facultad de medicina y Ciencias de la Salud de la Universidad de BarcelonaUniversidad de Barcelona Facultad de Medicina y Ciencias de La Salud: Universitat de Barcelona Facultat de Medicina i Ciencies de la Salut

\section{Montse Marqués}

Hospital Germans Trias i Pujol: Hospital Universitari Germans Trias i Pujol

\section{Isabel Salina}

Hospital Germans Trias i Pujol: Hospital Universitari Germans Trias i Pujol

\section{Federico Vázquez}

Hospital Germans Trias i Pujol: Hospital Universitari Germans Trias i Pujol

\section{Berta Soldevila}

Hospital Germans Trias i Pujol: Hospital Universitari Germans Trias i Pujol

\section{Raquel Ciriza}

Spanish association of Acromegaly

\section{Manel Puig-Domingo ( $\nabla$ mpuigd@igtp.cat)}

University Hospital Germans Trias i Pujol: Hospital Universitari Germans Trias i Pujol https://orcid.org/0000-0002-6744-7195

\section{Research Article}

Keywords: acromegaly, facial changes, Quality of life, psychosocial impact

Posted Date: February 7th, 2022

DOI: https://doi.org/10.21203/rs.3.rs-1321249/v1

License: (9) (1) This work is licensed under a Creative Commons Attribution 4.0 International License. Read Full License 


\section{Abstract}

Purpose: to study the potential relationship between disfiguring facial modifications and psychosocial and Quality of Life (QoL) impact in a group of acromegaly patients.

Methods: Thirty patients accepted to participate in this study $(n=13)$ women and $56.6 \%(n=17)$ men; mean age was $61.1 \pm 15.8$ and $56.3 \pm 12.4$ years, respectively. Variables studied included: a) Anxiety level, measured through the State-Trait Anxiety Questionnaire (STAI); b) Quality of life evaluation by AcroQoL; c) Self-esteem status through the Rosemberg Self-Esteem Scale and d) Facial acromegaly phenotypic changes evaluated from face photographs and scored by 8 trained endocrinologists.

Results: Gender differences were observed in Anxiety levels, with higher values in women than in men (trait: $6.1 \pm 2.2$ and $5.0 \pm 2.0(p=0.025)$; state: $8.2 \pm 1.1$ and $3.1 \pm 2.1(p=0.004)$, respectively. Also, there were differences in the global AcroQoL score, being 69.3 (SD \pm 17.7) for males and 51.1 (SD \pm 21.8$)$ for females $(p=0.004)$ and it was reflected in all dimensions. Self-Steem was similar in both groups. There were lower values at the face appearance scoring in women at pre-diagnostic phase ( $3.4 \pm 1.3$ vs. $4.75 \pm 1.5)$. A negative correlation was found between self-esteem and changes in facial scores at the pre-diagnostic and diagnostic periods $\left(r_{s}=-0.559, p=0.074\right)$, consistent with a high impact of facial changes in the psychologic status of the patients.

Conclusion: acromegaly facial changes negatively impact the psychosocial condition of these patients with maximal deleterious effects observed at the time of diagnosis; these disturbances persist over time despite disease control or curation and are of higher intensity in women.

\section{Introduction}

Acromegaly is a rare, chronic disease caused by excessive secretion of growth hormone (GH) secondary to a hormonally active adenoma of the anterior lobe of the pituitary gland. The annual incidence of acromegaly is $0.2-1.1$ cases per 100,000 inhabitants, and the prevalence in the general population is 2.813.7 cases per 100,000 people [1].

Acromegaly implies physical appearance changes, mostly of acral parts of the body, but being the face also highly disfigured by the disease. These facial changes are quite suggestive of the disease and sometimes are the factor precipitating and allowing the diagnosis through spontaneous recognition by a health professional. Acromegaly accounts for an important medical, psychological and social burden reflected by an impaired quality of life (QoL) of patients, affecting also the daily activities of their lives [2-4]. QoL impairment is an integrated consequence of the physical and psychologic impact of hypersecretion of $\mathrm{GH}$, which causes complications at the metabolic, respiratory, cardiovascular and skeletal levels $[5,6]$.

Several studies have associated acromegaly with a substantial psycho-emotional disturbed state. Its chronic nature or at least the persistence of sequelae at various organs and at the skeletal level after the 
disease is cured, may explain the associated psychological morbidity in patients with acromegaly $[7,8]$.

Even so, there are few studies that have analyzed the relationship between acromegaly and the level of anxiety, stress, self-esteem and / or quality of life $[9,10]$. In 1999, Webb and Badia developed a questionnaire on Quality of life in acromegalic patients (AcroQoL) $[11,12]$. Later studies showed how QoL scores were highly influenced by factors such as the age, the duration of the disease, radiotherapy, gender, and the hormonal levels, among others. In recent years, poor QoL condition has been confirmed in patients with acromegaly, mainly related to the physical and psychological comorbidities associated with the disease $[13,14]$.

Although early diagnosis can minimize the impact of the disease on health status, it is well known that an important delay in time to diagnose the disease exists. This delay is estimated to be in average of about 8 years in men and 10 in women[15] since initiation of the disease. An excessive delay in diagnosis generates additional psychosocial deterioration, increases the development of complications -including maximization of facial changes- and can have a direct impact on Health-related Quality of Life (HRQL).

So far, there are no investigations reporting potential correlations of the morphometric facial changes of acromegaly patients and their psychological impact and quality of life. For this reason, the aim of this study was to analyze the relationship of the psychosocial alterations and QoL, with the morphometric facial change's characteristics in acromegalic patients.

\section{Material And Methods}

A prospective cohort study was carried out in a Spanish university hospital, between September 2020 and February 2021. Patients with cured or medically controlled (normal GH and IGF-1) acromegaly under follow-up at the outpatient clinic were invited to participate in the study. The inclusion criteria were: patients $\geq 18$ years of age, with regular outpatient follow-up, being diagnosed of acromegaly and either cured or hormonally controlled through medical treatment.

After contacting 50 patients with follow-up at our center, 30 accepted to participate. The recruitment was carried out through a telephone contact, as well as during the regular scheduled visits at the outpatient clinic. Recruitment period extended from October to December 2020.

The study variables were the following: a) Sociodemographic: age, sex, educational level, work activity and social situation; b) Anthropometric: weight, height, Body Mass Index (BMI); c) Variables related to the acromegaly conditions: tumor size at diagnosis, comorbidities, treatments performed (surgery, radiotherapy, and medical treatment used), recurrence rate, and disease activity; d) Anxiety Level, measured through the State-Trait Anxiety Questionnaire (STAI); f) Quality of life evaluation through AcroQoL; g) Self-esteem status, using the Rosemberg Self-Esteem Scale and g) Facial acromegaly phenotypic changes were evaluated by examination of photographs provided by the participants by 8 trained endocrinologists which gave a score based on a Likert scale from 0 to 10 ( $0=$ no facial modification, $10=$ maximum facial acromegaly phenotypic modifications), reflecting the general 
acromegaly facial burden of each picture. Specifically, visual morphometry was performed from 3 facial photographs which included one before the diagnosis (Pre-diagnosis), another one performed during the diagnosis period (Diagnosis) and a final one corresponding to the period of current follow-up in which the disease was either cured or under GH hypersecretion control assessed by normal circulating GH and IGF1 ; each photograph was individually scored by a group of 8 trained endocrinologists. For evaluation of facial changes, particular attention was paid to the modifications at the tip of the nose, the margin of the eyes, cheekbones, mouthwashes and the margin of the nostrils; facial soft tissue changes were also considered although patients were either cured or under medical control, thus minor changes were expected to be found at the post-diagnostic time, but were have to be present at the pre-diagnostic and diagnostic images. As previous publications reported greater enlargement of nasofrontal angles and greater mento-labial angles for females, these sexually dimorphic characteristics were specially evaluated. The concordance between physician's scoring was also assessed using the intraclass correlation index.

The following instruments and questionnaires were used for psychologic and QoL assessment:

a) Anxiety was measured through the State-Trait Anxiety Questionnaire (STAI); the State and Trait Anxiety Inventory (STAI) measures two dimensions of anxiety: state anxiety and trait anxiety. It consists of a brief 6-item reduced version of the original STAI (Spielberger et al., 1983), obtaining good psychometric measurement properties and a consistent structure $(\alpha=0,80$ in state anxiety and $a=0.88$ in trait anxiety). This reduced version comprises six items per scale with a minimum score of 0 and a maximum of 18 . This short version has been shown to have good validity in different populations (Guillén-Riquelme and Buela-Casal, 2013). b) Quality of life evaluation through AcroQoL; The AcroQoL scale is a disease-specific questionnaire to assess health-related quality of life in patients with acromegaly. The scale mainly evaluates two dimensions: physical function and psychological well-being of the patient. The psychological scale is subdivided into two subscales regarding appearance and personal relationships, containing seven items each. The questionnaire consists of 22 questions, each of which is answered on a 5-point Likert scale that measures the frequency of occurrence (ranging from "always" to "never") or the degree of agreement with the elements (ranging from "strongly agree" to "strongly disagree"). The highest achievable score is 110 , which is indicative of an excellent quality of life, while the lowest score is 22 . The scale has been translated and validated in the Spanish population, with a Cronbach's $a>0.8$, which indicates high reliability and internal consistency (16). c) Self-esteem status, using the Rosemberg SelfEsteem Scale; this questionnaire explores personal self-esteem as the feelings of personal worth and selfrespect. The scale consists of 10 items, each of which is answered on a 5-point Likert scale (1 Strongly agree, 2 Agree, 3 Disagree, 4 Strongly disagree), five are stated positively and five negatively. Scores of 30 to 40 points indicate high self-esteem, 26 to 29 points, average self-esteem and less than 25 points low self-esteem. The scale has been translated and validated in Spanish. The internal consistency of the scale is between 0.76 and 0.87 (17).

All clinical variables were included in a Data Collection Form (DCF), and were retrieved from the electronic clinical history of the hospital, which contains all the clinical, pharmacological and follow-up variables of 
acromegalic patients. The facial photos provided by all participants were also included in the DCF for the study purposes. In the DCF each patient and its personal information was registered used an anonymized code following the indication and supervision of the data protection officer of the institution.

The study was approved by the Clinical Ethics Committee (registry code PI-19-247). Written informed consent was obtained from all participants.

For the description of all quantitative variables, the mean and standard deviation (SD), or the median and the interquartile range were calculated. Qualitative variables are presented as frequencies and percentages. Inferential analysis was carried out based on the Spearman or Pearson correlation coefficient. A significant level of 0.05 was considered in all tests. All data were analyzed with IBM SPSS software version 27.

\section{Results}

\section{Patient characteristics}

The study cohort thus, consisted in 30 acromegaly patients followed at our institution, in which 13 (43.3\%) were women and 17 were men (56.6\%); mean age was $61.6 \pm 16.4$ and $55.5 \pm 11.2$ years, respectively. The sociodemographic profiles regarding education, place of residence and marital status did not vary significantly between gender. Mean BMI was $35.3 \mathrm{~kg} / \mathrm{m}^{2}$ (37 vs 33.5 respectively in men and women). According to the diameter of the tumor at the time of diagnosis, there were $7(28 \%)$ microadenoma $(<10 \mathrm{~mm})$, and $18(72 \%)$ macroadenoma $(>10 \mathrm{~mm})$. Description of the cohort characteristics is presented in Table 1. Fifteen patients ( $50 \%$ of the sample) were in complete remission criteria after surgery, while the other 15 patients were under medical treatment with normalization of hormonal parameters at the time of the study. 
Table 1

Sociodemographic, anthropometric and clinic variables

SOCIODEMOGRAPHIC VARIABLES

\begin{tabular}{|c|c|c|c|c|}
\hline & & Male & Female & $\mathrm{p}$ \\
\hline Sex & & $17(56.6 \%)$ & $13(43.3 \%)$ & \\
\hline Age (mean $\pm S D$ ) whole cohort & $58.2 \pm 13.8$ & & & \\
\hline Age (mean $\pm S D)$ & & $55.5(11.2)$ & $61.6(16.4)$ & \\
\hline \multirow[t]{4}{*}{ Marital Status } & Married & $10(76.9 \%)$ & $7(58.3 \%)$ & $0.296^{*}$ \\
\hline & Widower & & $2(16.7 \%)$ & \\
\hline & Single & $2(15.4 \%)$ & $3(25.0 \%)$ & \\
\hline & Divorced & $1(7.7 \%)$ & 0 & \\
\hline \multirow[t]{4}{*}{ Working status } & Active & $7(50.0 \%)$ & $2(16.7 \%)$ & $0.173^{\star}$ \\
\hline & Not working & 0 & $2(16.7 \%)$ & \\
\hline & Retired & $6(42.9 \%)$ & $6(50.0 \%)$ & \\
\hline & Disabled & $1(7.1 \%)$ & $2(16.7 \%)$ & \\
\hline \multirow[t]{3}{*}{ Educational status } & Primary & $3(33.3 \%)$ & $4(44.4 \%)$ & $0.614^{\star}$ \\
\hline & High school & $5(55.6 \%)$ & $3(33.3 \%)$ & \\
\hline & University & $1(11.1 \%)$ & $2(22.2 \%)$ & \\
\hline \multicolumn{5}{|l|}{ ANTROPOMETRIC VARIABLES } \\
\hline \multirow[t]{2}{*}{ Weight } & Pre & $90.5(8.22)$ & $71.1(13.7)$ & $0.032 * \star$ \\
\hline & Post & $93.0(14.17)$ & $76.5(17.0)$ & $0.035^{\star \star}$ \\
\hline Height & & $174.2(5.7)$ & $163.1(7.6)$ & $0.026 * \star$ \\
\hline Body mass index (BMI) & & $37.0(0.0)$ & $33.5(0.7)$ & \\
\hline \multirow[t]{3}{*}{ CLINICAL VARIABLES } & & & & $\mathbf{p}$ \\
\hline & & Male & Female & \\
\hline & & $17(56.6 \%)$ & $13(43.3 \%)$ & \\
\hline \multirow[t]{2}{*}{ Tumor size } & Microadenoma & $4(26.7 \%)$ & $3(30.0 \%)$ & $0.600^{\star \star \star *}$ \\
\hline & Macroadenoma & $11(73.3 \%)$ & $7(70.0 \%)$ & \\
\hline Relapse & Yes & $10(58.8 \%)$ & 1 (12.5\%) & $0.030 * * *$ \\
\hline
\end{tabular}




\begin{tabular}{|c|c|c|c|c|}
\hline \multicolumn{5}{|c|}{ SOCIODEMOGRAPHIC VARIABLES } \\
\hline & No & $5(29.4 \%)$ & $7(87.5 \%)$ & \\
\hline \multirow[t]{2}{*}{ Remission } & Cured & $7(41.2 \%)$ & $8(61.5 \%)$ & $0.400 * * *$ \\
\hline & Activo under control & $10(58.8 \%)$ & $5(38.5 \%)$ & \\
\hline \multirow[t]{2}{*}{ Surgery } & Yes & $15(65.2 \%)$ & $8(34.8 \%)$ & $0.081^{\star \star \star}$ \\
\hline & No & $2(28.6 \%)$ & $5(71.4 \%)$ & \\
\hline \multirow[t]{3}{*}{ Surgical modality } & Transesfenoidal & $12(63.2 \%)$ & $7(36.8 \%)$ & $0 . *$ \\
\hline & Exeresis & $1(100 \%)$ & $0(0.0 \%)$ & \\
\hline & Transfrontal & $1(100 \%)$ & $0(0.0 \%)$ & \\
\hline \multirow[t]{2}{*}{ Second surgery } & Yes & $2(100 \%)$ & $0(0.0 \%)$ & $0.223^{*}$ \\
\hline & No & $15(53.6 \%)$ & $13(46.4 \%)$ & \\
\hline \multirow[t]{2}{*}{ Radiotherapy } & Yes & $4(66.7 \%)$ & $2(33.3 \%)$ & $0.701^{* * *}$ \\
\hline & No & $10(58.8 \%)$ & $7(41.2 \%)$ & \\
\hline
\end{tabular}

At enrollment, the percentages of patients who ever received surgery, radiation therapy, somatostatin analogs, and dopamine agonist were 76.6\% $(n=23), 26 \%(n=6), 53.3 \%(n=16), 10 \%(n=5)$ respectively (see Table 1).

\section{Psychosocial outcomes and gender}

The AcroQoL scale (range: 22-110) results at the time of the study for the whole cohort showed mid-range values in the physical domains, being of $54.80 \pm 29.06$, as well as in the psychological domain of the physical aspect, which was $65.20 \pm 19.6$, and also in the social interaction where the result was more in the upper range, being of $75.20 \pm 21.7$. Gender differences were found in the Global AcroQoL score $(p=$ 0.018 ) and in the physical dimension $(p=0.004)$, indicating better scores for males, as shown in Table 2 . Regarding the Rosemberg scale, the results indicated a relatively high auto-esteem state for the whole cohort, as the median was $2.63 \pm 0.66$ (maximal value 3 ), but without showing sexual dimorphism $(p=0,850)$. 
Table 2

Psychosocial outcomes and gender

\begin{tabular}{|c|c|c|c|c|}
\hline \multicolumn{5}{|l|}{ AcroQoL } \\
\hline \multirow[t]{2}{*}{ Variable } & $(n=30)$ & Male & Female & $P$ \\
\hline & $\begin{array}{l}\text { Mean } \pm \\
\text { SD }\end{array}$ & $\begin{array}{l}\mathrm{n}=13 \\
(43.4 \%)\end{array}$ & $\begin{array}{l}n=17 \\
(56.6 \%)\end{array}$ & $\begin{array}{l}(T- \\
\text { test })\end{array}$ \\
\hline \multicolumn{5}{|l|}{ ACROQoL Global } \\
\hline Mean \pm SD & $\begin{array}{l}61.4 \\
(21.3)\end{array}$ & $69.3(17.7)$ & $51.1(21.8)$ & 0.018 \\
\hline $\mathrm{N}$ & 30 & 17 & 13 & \\
\hline \multicolumn{5}{|l|}{ Physical dimension } \\
\hline Mean \pm SD & $\begin{array}{l}54.8 \\
(29.6)\end{array}$ & $67.6(23.4)$ & $38.0(29.0)$ & 0.004 \\
\hline $\mathrm{N}$ & 30 & 17 & 13 & \\
\hline \multicolumn{5}{|l|}{ Phsycological dimension } \\
\hline Mean \pm SD & $\begin{array}{l}65.2 \\
(19.6)\end{array}$ & 70.1(17.5) & $58.6(21.1)$ & 0.113 \\
\hline $\mathrm{N}$ & 30 & 17 & 13 & \\
\hline \multicolumn{5}{|l|}{ Phsycological dimension (appearance): } \\
\hline Mean \pm SD & $\begin{array}{l}54.8 \\
(23.6)\end{array}$ & $60.9(18.9)$ & $46.7(27.3)$ & 0.104 \\
\hline $\mathrm{N}$ & 30 & 17 & 13 & \\
\hline \multicolumn{5}{|l|}{$\begin{array}{l}\text { Phsycological dimension (social } \\
\text { relationship) }\end{array}$} \\
\hline Mean \pm SD & 75.2(21.7) & $79.4(23.3)$ & $69.7(19.0)$ & 0.235 \\
\hline $\mathrm{N}$ & 30 & 17 & 13 & \\
\hline \multicolumn{5}{|l|}{ Rosemberg scale } \\
\hline Auto esteem Mean \pm SD & $2.6(0.6)$ & $2.6(0.6)$ & $2.6(0.7)$ & 0.850 \\
\hline $\mathrm{N}$ & 30 & 17 & 13 & \\
\hline \multicolumn{5}{|l|}{ STAI scale } \\
\hline \multirow{2}{*}{$\begin{array}{l}\text { Anxiety scale questionnaire (trait) Mean } \pm \\
\text { SD }\end{array}$} & $5.4(2.1)$ & $5.0(2.0)$ & $6.1(2.2)$ & 0.225 \\
\hline & 30 & 17 & 13 & \\
\hline
\end{tabular}




\begin{tabular}{|lllll|}
\hline AcroQoL & & & & \\
\hline Anxiety scale questionnaire (state) Mean \pm & $7.0(2.0)$ & $6.1(2.1)$ & $8.2(1.1)$ & 0.004 \\
SD & 30 & 17 & 13 & \\
N & & & & \\
\hline
\end{tabular}

The STAI scale results showed a relatively high level of anxiety, as about $80 \%$ of the participants showed a score higher than 5.47 in the STAI-S and 7.03 for the STAI-E. Women showed higher anxiety levels according to State-R and State-E; thus, anxiety scored $7.03 \pm 2.05$ as a "state" and $5.47 \pm 2.16$ as a "trait" and both were statistically different compared to men $(p=0.004)$.

\section{Facial Detection outcomes and gender}

Facial acromegaly changes were evaluated individually by 8 endocrinologists which scored the severity of phenotypical changes from 0 to 10, at three different time-points of the biographical evolution of each patient: before diagnosis, at diagnosis and after diagnosis. The intraclass correlation coefficient was $88 \%$ at the pre-diagnostic situation, $87 \%$ at diagnosis and $88 \%$ after diagnosis. Scores obtained at these three different time-points were $4.32 \pm 1.57,5.80 \pm 1.70,6.44 \pm 1.57$. Facial changes showed an increase in their scores of about 2 points from the pre-diagnostic to the diagnostic period, but is remarkable that all the subjects were having identifiable acromegaly facial changes even 5 years before diagnosis, which was the mean time of pre-diagnostic provided picture. In addition, it is noteworthy that the intensity of facial changes was higher in men compared to women with a mean score of $6.9 \pm 1.40$ vs $5.3 \pm 1.40$ in women, although statistically significant differences were only detected at post diagnostic phase $(\mathrm{p}=$ 0.034) (see Table 3).

Table 3

Facial Detection outcomes and gender

\begin{tabular}{|c|c|c|c|c|}
\hline \multicolumn{5}{|c|}{ FACE APPEARANCE SCORING } \\
\hline \multirow[t]{3}{*}{ scale } & Whole cohort & Males & Females & $p$ \\
\hline & Mean \pm SD & Mean \pm SD & Mean \pm SD & \\
\hline & $\mathrm{n}$ & $\mathrm{n}$ & $\mathrm{n}$ & \\
\hline \multirow[t]{2}{*}{ Pre-diagnostic } & $4.3(1.5)$ & $4.75(1.55)$ & $3.4(1.3)$ & 0.2 \\
\hline & 15 & 10 & 5 & \\
\hline \multirow[t]{2}{*}{ Diagnostic } & $5.8(1.7)$ & $5.86(1.92)$ & $5.69(1.38)$ & 0.9 \\
\hline & 19 & 12 & 7 & \\
\hline \multirow[t]{2}{*}{ Post-diagnostic } & $6.3(1.5)$ & $6.9(1.4)$ & $5.3(1.4)$ & 0.03 \\
\hline & 19 & 12 & 7 & \\
\hline
\end{tabular}




\section{Correlation between the psychosocial outcomes and facial scores}

The main finding observed was a negative correlation between self-esteem and changes in facial scores at the pre-diagnostic and diagnostic periods which showed a statistical trend $\left(r_{s}=-0.559, p=0.074\right)$, consistent with a high impact of facial changes in the psychologic status of the patients over time (Table 4). Before diagnosis self-esteem showed a positive correlation while it turned to negative at the time of diagnosis and follow-up period $\left(r_{s}=0.05,-0.35\right.$ and -0.39 respectively) indicating the negative effect of facial changes produced during the disease progression and the recognition that acromegaly exerts deleterious facial changes given to patients as medical information at the time of diagnosis. Regarding AcroQoL scores related to facial changes, a different trend was observed compared to self-esteem evolution, with a high negative correlation at diagnosis with a $r_{s}=-0.59$, and falling to -0.24 at postdiagnosis period. 
Table 4

Correlation between psychosocial and face appearance scoring

\section{Psychosocial and face appearance scoring correlations}

\begin{tabular}{|llll|}
\hline Scale & & $\mathbf{r}$ & $\mathbf{p}$ \\
\hline Pre-diagnostic & AcroQoL & 0.15 & 0.59 \\
\cline { 2 - 4 } & Self-esteem & 0.05 & 0.82 \\
\cline { 2 - 4 } & STAI_questionnaire trait & -0.258 & 0.31 \\
\cline { 2 - 4 } & STAI_questionnaire scale & -0.14 & 0.60 \\
\hline Diagnostic & AcroQoL & -0.59 & 0.81 \\
\cline { 2 - 4 } & Self-esteem & -0.35 & 0.2 \\
\cline { 2 - 4 } & STAl_questionnaire trait & -0.2 & 0.4 \\
\cline { 2 - 4 } & STAI_questionnaire state & -0.15 & 0.50 \\
\hline Post-diagnostic & AcroQoL & -0.24 & 0.33 \\
\cline { 2 - 4 } & Self esteem & -0.39 & 0.1 \\
\cline { 2 - 4 } & STAI_questionnaire trait & -0.21 & 0.40 \\
\cline { 2 - 4 } & STAI_questionnaire state & -0.15 & 0.5 \\
\hline Facial score changes before and after Diagnóstico-Pre & AcroQoL & -0.369 & 0.264 \\
& Self-esteem & -0.559 & 0.074 \\
& STAI_questionnaire trait & -0.293 & 0.40 \\
& STAI_questionnaire state & 0.031 & 0.90 \\
\hline
\end{tabular}

Finally, anxiety as measured by STAI showed for both STAI-R and STAI-E a stable weak negative linear association in the three different periods $\left(r_{s}=-0.15,-0.14\right.$ and -0.15 , respectively) (see Table 4 ).

\section{Discussion}

There are some studies reporting the existence of psychosocial alterations in people affected by acromegaly. The psychosocial impact previously reported in these patients refers to a greater emotional lability, a decreased quality of life assessed by AcroQoL and an increased anxiety state and a lower selfesteem $[9,16]$. These psychological disturbances can be attributed to the deleterious effect that these patient's general health status suffers as a consequence of the chronic condition of acromegaly disease, either during the active state but also after cure or control due to associated comorbidities and sequelae, but also attributable to facial disfigurement, which in late diagnosis may be even cruel. The loss of self- 
image and disfigurement may contribute to a tendency towards depression and social isolation, as people living with this situation may self-protect from social stigmatization by diminishing social exposure. As facial changes due to active acromegaly take years to be established, the non-diagnosed affected people use to feel these face changes like normal changes with time goes on. In recent years different studies have analyzed the morphometric facial changes developed in acromegalic patients, but in these reports there is no mention regarding the relationship between the morphometric score and the potential psychosocial consequences [17-19].

Our results show that self-esteem correlated with facial scores over time, thus making feasible that they may contribute to aggravate it. The impact of diagnosis is undoubtedly high and the patient's awareness of the irreversibility of acromegaly facial bone changes makes it hard to accept for many. Women are or may be particularly psychologically shocked at this moment and this impact may persist for years, sometimes with never recovering from such a situation. We found a particular negative psychological impact in women, in which a worse quality of life according to AcroQol Global and Physical dimension results compared to men were found. Likewise, anxiety levels in women with respect to that found in men showed significant differences, being higher in the former, as also previously reported by others [20, 21].

After diagnosis and particularly after curation or control of the disease, the QoL does not present significant changes even if the facial changes affecting soft tissue may ameliorate, thus explaining the negative linear association between AcroQoL and facial scoring either in the diagnostic and postdiagnostic phase. The fact of having a firm diagnosis allowing a pharmacological and/or surgical treatment which has a positive influence in the disease is felt as a gain, but it does not affect QoL. The present study also shows that patients present moderate to high levels of self-esteem, as also reported by Dimopoulu et al [22]. Changes at the facial level in acromegalic patients occur slowly and progressively, with people adapting to modifications and accommodating its perception under a state of self-image acceptance. This would justify the levels of self-esteem registered in the present study, as well as the negative linear association that appears in the diagnostic and post-diagnostic phase in the self-esteem results [19]. Finally, the negative linear association between anxiety levels and facial modifications stands out. Different authors $[9,16]$ postulate that anxiety levels remain high throughout the different phases of the disease. The present research provides a longitudinal analysis of the morphometric modifications not previously reported. It establishes facial records in three different time-points of the patient biography (before, during and after diagnosis). To the best of our knowledge, there are no studies performing a longitudinal evaluation of these modifications over time. We found greater facial morphometric differences in men than in women, especially in the post-diagnosis phase, as also evidenced by different reports, which confirm that the morphometric progression is irreversible and show a sexual dimorphism $[21,23,24]$. Likewise, other findings confirm that morphometric modifications remained significantly altered two years after remission in cured patients $[25,26]$, as we did in the present work. The scoring process carried out by endocrinologists showed a high intraclass correlation coefficient, which additionally opens new lines of research with the creation of an artificial intelligence software system through 3D images that can establish an early diagnosis in acromegalic patients. Such 
a possibility may shorten the delay in the detection of the disease and minimize the irreversible effects of the disease progression and its many associated comorbidities and even mortality [20].

Our results on the psychosocial condition of participants may have been modulated when not aggravated during the COVID pandemic, when the study took place. This could be related to the lack of usual followup due to confinement requirements, as reported by different authors [27-29]. Thus, we cannot rule out that the confinement caused by the COVID-19 pandemic during the second outbreak in our geographical area may have potentially contributed to an increase in the state of anxiety in acromegalic patients, although we believe that this exceptional situation does not devaluate the results obtained. Another limitation of the present study is the relatively small sample of participants, which was developed in a single center. On the other side, strengths were the good concordance obtained in the facial scoring and the reliability of the validated instruments used to explore psychosocial characteristics and QoL of the participants.

In conclusion, acromegaly facial changes negatively impact the psychosocial condition of these patients with maximal deleterious effects at the time of diagnosis; these disturbances persist over time despite curation and are of higher intensity in women.

\section{Declarations}

\section{Consent for publication}

Not applicable

\section{Availability of data and materials}

Not applicable

\section{Competing interests}

The authors declare that they have no competing interests

\section{Funding}

This study doesn't have any funding support.

\section{Author Contributions}

All authors contributed to the study conception and design. Material preparation, data collection and analysis were performed by [Maria-Antonia Martínez-Momblan], [Manel Puig-Domingo] and [Sergio Alonso-Fernández]. The first draft of the manuscript was written by [Maria-Antonia Martínez-Mombaln] and all authors commented on previous versions of the manuscript. All authors read and approved the final manuscript." 


\section{ACKNOWLEDGMENTS}

This research did not receive any specific grant from funding agencies in the public, commercial, or notfor-profit sectors. The authors would like to thank all the patients participating in this study and the endocrinologists that evaluated the facial pictures at Germans Trias Hospital (Eva Aguilera, Nuria Alonso, Clara Joaquin, Ma Teresa Julián, Silvia Pellitero, Alejandra Pérez Montes de Oca, Analia Ramos, Jordi Reverter).

\section{References}

1. Dineen R, Stewart PM, Sherlock M (2017) Acromegaly. QJM 110:411-420

2. Solomon E, Brănișteanu D, Dumbravă A, et al (2019) Executive functioning and quality of life in acromegaly. Psychology Research and Behavior Management 12:39-44. https://doi.org/10.2147/PRBM.S183950

3. Gatto F, Campana C, Cocchiara F, et al (2019) Current perspectives on the impact of clinical disease and biochemical control on comorbidities and quality of life in acromegaly. Reviews in Endocrine and Metabolic Disorders 20:365-381. https://doi.org/10.1007/s11154-019-09506-y

4. De Kort AJ, Postulart D, Wetzer GAAM, Roerink SHPP (2016) Acromegalic, herkenning van een zeldzame ziekte in de psychiatrie [Acromegaly: recognition of a rare disease in psychiatric practice]. Tijdschrift voor Psychiatrie 58:794-802

5. Pivonello R, Auriemma RS, Grasso LFS, et al (2017) Complications of acromegaly: cardiovascular, respiratory and metabolic comorbidities. Pituitary 20:46-62

6. Colao A, Grasso LFS, Di Somma C, Pivonello R (2019) Acromegaly and Heart Failure. Heart failure clinics 15:399-408. https://doi.org/10.1016/j.hfc.2019.03.001

7. Anagnostis P, Efstathiadou ZA, Charizopoulou M, et al (2014) Psychological profile and quality of life in patients with acromegaly in Greece. Is there any difference with other chronic diseases? Endocrine 47:564-571. https://doi.org/10.1007/s12020-014-0166-5

8. Mattoo SK, Bhansali AK, Gupta N, et al (2008) Psychosocial morbidity in acromegaly: a study from India. Endocrine 34:17-22. https://doi.org/10.1007/s12020-008-9112-8

9. Pantanetti P, Sonino N, Arnaldi G, Boscaro M (2002) Self image and quality of life in acromegaly. Pituitary 5:17-19. https://doi.org/10.1023/a:1022145116901

10. Hatipoglu E, Topsakal N, Atilgan OE, et al (2014) Impact of exercise on quality of life and body-self perception of patients with acromegaly. Pituitary 17:38-43. https://doi.org/10.1007/s11102-0130463-7

11. Webb SM, Badia X, Barahona MJ, et al (2008) Evaluation of health-related quality of life in patients with Cushing's syndrome with a new questionnaire. European journal of endocrinology 158:623630. https://doi.org/10.1530/EJE-07-0762

12. Webb SM, Prieto L, Badia X, et al (2002) Acromegaly Quality of Life Questionnaire (ACROQOL) a new health-related quality of life questionnaire for patients with acromegaly: development and 
psychometric properties. Clinical endocrinology 57:251-258. https://doi.org/10.1046/j.13652265.2002.01597.x

13. Chin SO, Chung $\mathrm{CH}$, Chung Y-S, et al (2015) Change in quality of life in patients with acromegaly after treatment with octreotide LAR: first application of AcroQoL in Korea. BMJ open 5:e006898. https://doi.org/10.1136/bmjopen-2014-006898

14. Oliveira B de A, Araújo B, Dos Santos TM, et al (2020) Health-related Quality of Life in Acromegaly Patients: Results from Generic and Disease-specific Questionnaires. Indian journal of endocrinology and metabolism 24:402-405. https://doi.org/10.4103/ijem.IJEM_401_20

15. Álvarez-Escolá C, Venegas-Moreno EM, García-Arnés JA, et al (2019) ACROSTART: A retrospective study of the time to achieve hormonal control with lanreotide Autogel treatment in Spanish patients with acromegaly. Endocrinologia, diabetes y nutricion 66:320-329. https://doi.org/10.1016/j.endinu.2018.12.004

16. Gu J, Xiang S, He M, et al (2020) Quality of Life in Patients with Acromegaly before and after Transsphenoidal Surgical Resection. International journal of endocrinology 2020:5363849. https://doi.org/10.1155/2020/5363849

17. Learned-Miller E, Lu Q, Paisley A, et al (2006) Detecting acromegaly: screening for disease with a morphable model. Medical image computing and computer-assisted intervention: MICCAI. International Conference on Medical Image Computing and Computer-Assisted Intervention 9:495503. https://doi.org/10.1007/11866763_61

18. Miller RE, Learned-Miller EG, Trainer P, et al (2011) Early diagnosis of acromegaly: computers vs clinicians. Clinical endocrinology 75:226-231. https://doi.org/10.1111/j.1365-2265.2011.04020.x

19. Wang M-H, Lin J-D, Chang C-N, Chiou W-K (2017) Acromegaly determination using discriminant analysis of the three-dimensional facial classification in Taiwanese. Neuro endocrinology letters 38:301-309

20. Park SH, Ku CR, Moon JH, et al (2018) Age- and Sex-Specific Differences as Predictors of Surgical Remission Among Patients With Acromegaly. The Journal of clinical endocrinology and metabolism 103:909-916. https://doi.org/10.1210/jc.2017-01844

21. Imran SA, Tiemensma J, Kaiser SM, et al (2016) Morphometric changes correlate with poor psychological outcomes in patients with acromegaly. European journal of endocrinology 174:41-50. https://doi.org/10.1530/EJE-15-0888

22. Dimopoulou C, Leistner SM, Ising M, et al (2017) Body Image Perception in Acromegaly Is Not Associated with Objective Acromegalic Changes but Depends on Depressive Symptoms. Neuroendocrinology 105:115-122. https://doi.org/10.1159/000448519

23. Guo X, Meng T, Huang J, et al (2018) 3D Facial Analysis in Acromegaly: Gender-Specific Features and Clinical Correlations. Frontiers in endocrinology 9:722.

https://doi.org/10.3389/fendo.2018.00722

24. Meng T, Guo X, Lian W, et al (2020) Identifying Facial Features and Predicting Patients of Acromegaly Using Three-Dimensional Imaging Techniques and Machine Learning. Frontiers in 
endocrinology 11:492. https://doi.org/10.3389/fendo.2020.00492

25. Du F, Chen Q, Wang $X$, et al (2021) Long-term facial changes and clinical correlations in patients with treated acromegaly: a cohort study. European journal of endocrinology 184:231-241. https://doi.org/10.1530/EJE-20-0962

26. Wagenmakers MAEM, Roerink SHPP, Maal TJJ, et al (2015) Three-dimensional facial analysis in acromegaly: a novel tool to quantify craniofacial characteristics after long-term remission. Pituitary 18:126-134. https://doi.org/10.1007/s11102-014-0565-x

27. Chen L, Zhao H, Razin D, et al (2021) Anxiety levels during a second local COVID-19 pandemic breakout among quarantined people: A cross sectional survey in China. Journal of psychiatric research 135:37-46. https://doi.org/10.1016/j.jpsychires.2020.12.067

28. Bigalke JA, Greenlund IM, Carter JR (2020) Sex differences in self-report anxiety and sleep quality during COVID-19 stay-at-home orders. Biology of sex differences 11:56. https://doi.org/10.1186/s13293-020-00333-4

29. Durcan E, Turan S, Sahin S, et al (2021) Psychosocial effects and clinic reflections of the COVID-19 outbreak in patients with acromegaly and Cushing's disease. Pituitary. https://doi.org/10.1007/s11102-021-01136-5

\section{Supplementary Files}

This is a list of supplementary files associated with this preprint. Click to download.

- Highlights.docx 